\title{
Dietary Acid Intake and Kidney Disease Progression in the Elderly
}

\author{
Eiichiro Kanda ${ }^{a}$ b Masumi $\mathrm{Ai}^{\mathrm{c}}$ Renjiro Kuriyama ${ }^{d}$ Masayuki Yoshida ${ }^{\mathrm{b}}$ \\ Tatsuo Shiigai ${ }^{\mathrm{e}}$ \\ ${ }^{a}$ Department of Nephrology, Tokyo Kyosai Hospital, ${ }^{b}$ Life Science and Bioethics Research Center, ${ }^{\mathrm{c}}$ Department of \\ Insured Medical Care Management, Tokyo Medical and Dental University Hospital, ' Kokubunji Minamiguchi Clinic, \\ Tokyo, and eShiigai Clinic, Ibaraki, Japan
}

\section{Key Words}

Acidosis - Bicarbonate - Chronic kidney disease - Elderly · Low protein diet $\cdot$ Net endogenous acid production

\begin{abstract}
Background/Aims: Non-volatile acid is produced by metabolism of organic sulfur in dietary protein, and promotes kidney damage. We investigated the role of dietary acid load, in terms of net endogenous acid production (NEAP), in chronic kidney disease (CKD) progression. Methods: 217 CKD patients on low-protein diet with a normal serum bicarbonate level were enrolled in this retrospective cohort study in Japan. The primary outcome was $25 \%$ decline in estimated glomerular filtration rate (eGFR) or start of dialysis. Their NEAP was measured every 3 months. The patients were categorized into four groups on the basis of quartiles of NEAP every 3 months. The groups were treated as time-dependent variables. Results: The average age (SD) was 70.6 (7.1) years; eGFR 23.5 (14.2) $\mathrm{ml} / \mathrm{min} / 1.73 \mathrm{~m}^{2}$. Analysis using extended Cox models for the NEAP groups adjusted for baseline characteristics (referring to group 1 showing the lowest NEAP) showed that high NEAP was associated with a high risk of CKD progression; group 2, adjusted hazard ratio (HR) 3.930 (95\% confidence interval (Cl) 1.914, 8.072); group 3, adjusted HR 4.740 (95\% Cl 2.196, 10.288); group 4, adjusted HR 4.303 $(95 \% \mathrm{Cl} 2.103,8.805)$. Logistic regression analysis adjusted
\end{abstract}

\begin{tabular}{ll}
\hline KARGER & $\begin{array}{l}\text { ( ) 2014 S. Karger AG, Basel } \\
0250-8095 / 14 / 0392-0145 \$ 39.50 / 0\end{array}$ \\
$\begin{array}{l}\text { E-Mail karger@karger.com } \\
\text { www.karger.com/ajn }\end{array}$ & $\begin{array}{l}\text { This is an Open Access article licensed under the terms of the } \\
\text { Creative Commons Attribution-NonCommercial 3.0 Un- } \\
\text { ported license (CC BY-NC) (www.karger.com/OA-license), } \\
\text { applicable to the online version of the article only. Distribu- } \\
\text { tion permitted for non-commercial purposes only. }\end{array}$
\end{tabular}

for baseline characteristics showed that the occurrence of hypoalbuminemia or hyperkalemia was associated with low serum bicarbonate level and the presence of complications at baseline, but not with NEAP. Conclusion: In elderly CKD patients, our findings suggest that high NEAP is independently associated with CKD progression. The decrease in NEAP may be an effective kidney-protective therapy.

(c) 2014 S. Karger AG, Basel

\section{Introduction}

As the number of functioning nephrons decreases in chronic kidney disease (CKD), the total ammonium excretion level begins to decrease, which leads to net retention of hydrogen ions and subsequently to metabolic acidosis $[1,2]$. Metabolic acidosis leads to CKD progression [3]. Observational studies showed an association between a low serum bicarbonate level and progression of kidney diseases [4-8].

Diet affects the acid-base balance [9]. Net endogenous acid production (NEAP) is the difference between endogenous acid production and the input of alkali absorbed in diet, and represents the total amount of non-volatile acid that is excreted to maintain the acid-base balance [10]. It has been reported that NEAP is estimated from protein intake and potassium excretion levels [11]. An observa- 
tional study, the African-American Study of Kidney Disease and Hypertension (AASK), showed that high NEAP is associated with low serum bicarbonate level and rapid decrease in glomerular filtration rate (GFR) $[12,13]$.

The CKD practice guideline of the Japanese Society of Nephrology recommends a low-protein diet to retard CKD progression in patients with stage 3-5 CKD [14]. However, to the best of our knowledge, there has been no report on the relationship between NEAP and CKD progression in CKD patients on a low-protein diet at the treatment strategy. For NEAP to be clinically useful, in this retrospective cohort study of elderly non-dialysis-dependent CKD patients on a low-protein diet with normal serum bicarbonate levels, we evaluated the relationship between NEAP and CKD progression. Moreover, we also investigated the occurrence of complications such as hypoalbuminemia or hyperkalemia.

\section{Materials and Methods}

\section{Study Design and Study Population}

This was a retrospective cohort study of non-dialysis-dependent CKD patients who were treated from 2009 to 2012 at Shiigai Clinic, Ibaraki, Japan. The observation period was 1 year. This study was approved by the Ethics Committee of Tokyo Kyosai Hospital, Tokyo, Japan. Patients were eligible for inclusion in this study when they had given their informed consent, were at least 60 years of age as of December 1, 2009, diagnosed as having CKD on the basis of the criteria of the Japanese Society of Nephrology, had an estimated GFR (eGFR) of $60 \mathrm{ml} / \mathrm{min} / 1.73 \mathrm{~m}^{2}$ or lower, and had never been treated by dialysis or undergone transplantation [14]. They usually visited the Shiigai Clinic once a month. Patients who were treated for dementia, lung diseases, chronic heart failure, or cancer were excluded. We treated CKD as a general practice of the clinic following the CKD practice guideline of the Japanese Society of Nephrology [14]. A high serum bicarbonate level was treated in accordance with the K/DOQI guidelines 2000 [15]. The serum bicarbonate level was maintained at $>21 \mathrm{mEq} / \mathrm{l}$ by administration of only sodium bicarbonate [15]. eGFR was calculated using the formula adopted by the Japanese Society of Nephrology and serum creatinine level [14]. Dietary therapy was prescribed to the patients: energy $27-39 \mathrm{kcal} / \mathrm{kg} /$ day; low-protein diet $(0.6-0.8 \mathrm{~g} / \mathrm{kg} /$ day); restricted salt intake ( $\geq 3$ and $<6 \mathrm{~g} /$ day); restricted potassium intake (stage $3, \leq 2,000 \mathrm{mg} /$ day; stages 4 and $5, \leq 1,500$ ) [14]. They ate traditional Japanese food based on boiled rice. To reduce protein intake, low-protein rice and bread were sometimes used. To reduce potassium intake, fresh fruit and vegetables were restricted, and boiling of vegetables was recommended.

\section{Data}

The baseline characteristics of the population were recorded at the time of the patients' initial evaluation in the nephrology clinic. The patients' demographics including age, gender, history of diabetes mellitus (DM), and body mass index (BMI); laboratory variables, namely the levels of serum albumin, sodium, potassium, cre- atinine, bicarbonate, $24 \mathrm{~h}$ urinary protein, protein intake estimated using Maroni's formula and $24 \mathrm{~h}$ potassium excretion, and the medications, namely renin-angiotensin-aldosterone system (RAAS) inhibitors (angiotensin-converting enzyme inhibitor (ACEI), angiotensin II receptor blockers (ARBs) or direct renin inhibitors), loop diuretics, and sodium bicarbonate were obtained from the medical records of the patients treated at the clinic. NEAP was estimated using the following formula: NEAP $(\mathrm{mEq} /$ day $)=$ $54.5 \times$ [protein intake $(\mathrm{g} /$ day) $/ 24 \mathrm{~h}$ potassium excretion level (mEq/day)] - 10.2 [11]. NEAP was recorded longitudinally every 3 months: baseline, third, sixth, ninth, and twelfth month. Routine serum biochemistry was carried out by standard methods at Shiigai Clinic. Serum bicarbonate level was measured by an enzymatic carbonate method using a Dimension Xpand analyzer (Siemens Healthcare Diagnostics, Inc., Tokyo, Japan). We defined the outcome as a decrease of $\geq 25 \%$ in eGFR or start of hemodialysis or peritoneal dialysis. All of the patients' data were followed up until they reached the outcome or after 1 year. The complications of NEAP were defined as the presence of hypoalbuminemia (serum albumin level $<3.5 \mathrm{~g} / \mathrm{dl}$ ) or hyperkalemia (serum potassium level $>5 \mathrm{mEq} / \mathrm{l})$.

\section{Statistical Analyses}

Normally distributed variables are presented as mean \pm SD, otherwise the median and interquartile range (IQR) are presented. Intergroup comparisons were performed using the $\chi^{2}$ test, one-way analysis of variance, and Kruskal-Wallis test as appropriate. Participants were categorized into four groups on the basis of the quartiles of NEAP. Patients' survival curves were derived by Kaplan-Meier analysis. Cox proportional hazards models were used to compare the risk of the outcome between a group with the lowest baseline NEAP and the groups with a high baseline NEAP. NEAP was then treated as a time-dependent variable and patients were categorized into four groups on the basis of the quartiles of NEAP every 3 months. Extended Cox models for the time-dependent NEAP groups were also examined similarly to the Cox proportional hazards models for the baseline NEAP groups. The Cox proportional hazards models and the extended Cox models were adjusted for several baseline covariates selected on the basis of $\mathrm{p}$ level in univariate Cox proportional hazards models $(\mathrm{p} \leq 0.1)$. The results are presented here as hazard ratios (HRs) with 95\% confidence interval (CI). The Cox proportional hazards models and the extended Cox models were then examined similarly after stratification on the basis of the serum bicarbonate level: groups with low serum bicarbonate levels, $22 \mathrm{mEq} / \mathrm{l}$ to the median of serum bicarbonate level $(26.15 \mathrm{mEq} / \mathrm{l})$, and groups with high serum bicarbonate levels, $>26.15 \mathrm{mEq} / \mathrm{l}$. To evaluate the effect of sodium bicarbonate use, after stratification of patients by NEAP and serum bicarbonate level (total eight stratums), we compared the survival curves for the same categories of NEAP and serum bicarbonate level between patients using sodium bicarbonate and those not using it by Kaplan-Meier analysis. The prevalence of complications was evaluated at baseline and in the third month. Univariate logistic regression analysis was performed to identify variables that were associated with the complications. Multivariate logistic regression analysis was then performed to identify variables that were independently associated with the complications by including factors that were previously selected on the basis of the results of univariate logistic regression analysis. The values of odds ratio (OR) and 95\% CI are 
Table 1. Baseline characteristics of patients categorized on the basis of quartiles of NEAP

\begin{tabular}{|c|c|c|c|c|c|c|}
\hline & All & Group 1 & Group 2 & Group 3 & Group 4 & $\mathrm{p}$ \\
\hline Number & 217 & 54 & 54 & 55 & 54 & \\
\hline Age, years & $70.6 \pm 7.1$ & $71.1 \pm 6.6$ & $70.2 \pm 7.1$ & $70.6 \pm 8.1$ & $70.5 \pm 6.5$ & 0.92 \\
\hline Diabetes mellitus (\%) & $68(31.3)$ & $11(20.4)$ & $22(40.7)$ & $15(27.3)$ & $20(37.0)$ & 0.09 \\
\hline $\mathrm{BMI}, \mathrm{kg} / \mathrm{m}^{2}$ & $22.5 \pm 2.7$ & $22.2 \pm 2.0$ & $22.6 \pm 2.8$ & $22.6 \pm 2.4$ & $22.4 \pm 3.6$ & 0.90 \\
\hline $\mathrm{eGFR}, \mathrm{ml} / \mathrm{min} / 1.73 \mathrm{~m}^{2}$ & $23.5 \pm 14.2$ & $29.1 \pm 14.8$ & $26.8 \pm 13.7$ & $23.6 \pm 14.5$ & $14.7 \pm 9.2$ & $0.0001^{*}$ \\
\hline 3 & $66(30.4)$ & $24(44.4)$ & $21(38.9)$ & $17(30.9)$ & $4(7.4)$ & \multirow[t]{3}{*}{$0.0001^{*}$} \\
\hline 4 & $72(33.2)$ & $18(33.3)$ & $20(37.0)$ & $17(30.9)$ & $17(31.5)$ & \\
\hline 5 & $79(36.4)$ & $12(22.3)$ & $13(24.1)$ & $21(38.2)$ & $33(61.1)$ & \\
\hline Albumin level, g/dl & $3.5 \pm 0.4$ & $3.6 \pm 0.4$ & $3.6 \pm 0.5$ & $3.5 \pm 0.5$ & $3.5 \pm 0.3$ & 0.18 \\
\hline Sodium level, mEq/l & $140.6 \pm 3.0$ & $140.4 \pm 3.2$ & $140.6 \pm 3.2$ & $141.1 \pm 3.1$ & $140.3 \pm 2.7$ & 0.47 \\
\hline Potassium level, mEq/l & $4.7 \pm 0.6$ & $4.7 \pm 0.5$ & $4.7 \pm 0.5$ & $4.7 \pm 0.5$ & $4.6 \pm 0.6$ & 0.51 \\
\hline Potassium excretion, $\mathrm{mEq} /$ day & $36.7 \pm 17.5$ & $55.9 \pm 19.2$ & $38.3 \pm 9.1$ & $32.2 \pm 8.2$ & $20.3 \pm 7.4$ & $0.0001^{*}$ \\
\hline $\mathrm{NEAP}, \mathrm{mEq} /$ day & $76.3 \pm 37.5$ & $41.5 \pm 8.3$ & $60.6 \pm 4.0$ & $76.4 \pm 5.5$ & $126.7 \pm 39.1$ & $0.0001^{*}$ \\
\hline RAAS inhibitor use (\%) & $179(82.5)$ & $45(83.3)$ & $42(77.8)$ & $47(85.5)$ & $45(83.3)$ & 0.75 \\
\hline Loop diuretic use (\%) & $76(35.0)$ & $13(24.1)$ & $16(29.6)$ & $21(38.2)$ & $26(48.2)$ & $0.049^{*}$ \\
\hline Sodium bicarbonate use (\%) & $47(21.7)$ & $8(14.8)$ & $8(14.8)$ & $10(18.2)$ & $21(38.9)$ & $0.005^{*}$ \\
\hline Decrease of $\geq 25 \%$ in eGFR (\%) & $49(22.6)$ & $8(14.8)$ & $11(20.4)$ & $16(29.1)$ & $14(25.9)$ & 0.30 \\
\hline Dialysis (\%) & $10(4.6)$ & $1(1.85)$ & $0(0)$ & $4(7.3)$ & $5(9.3)$ & 0.069 \\
\hline Outcome $^{\mathrm{a}}(\%)$ & $59(27.2)$ & $9(16.7)$ & $11(20.4)$ & $20(36.4)$ & $19(35.2)$ & $0.039^{*}$ \\
\hline Follow-up, days & $319.7 \pm 85.1$ & $335.9 \pm 71.4$ & $337.3 \pm 66.8$ & $300.6 \pm 102.0$ & $305.2 \pm 90.2$ & $0.034^{*}$ \\
\hline Hypoalbuminemia (\%) & $76(35.0)$ & $14(25.9)$ & $17(31.5)$ & $24(43.6)$ & $21(38.9)$ & 0.22 \\
\hline Hyperkalemia (\%) & $50(23.0)$ & $12(22.2)$ & $9(16.7)$ & $16(29.1)$ & $133(24.1)$ & 0.49 \\
\hline Complications ${ }^{\mathrm{b}}(\%)$ & $108(49.8)$ & $23(42.6)$ & $22(40.7)$ & $33(60.0)$ & $30(55.6)$ & 0.12 \\
\hline
\end{tabular}

Values are expressed as mean \pm SD. The levels of $24 \mathrm{~h}$ urine protein excretion and doses of sodium bicarbonate are presented with median and IQR. The values are compared between the groups by the $\chi^{2}$ test, one-way analysis of variance, and Kruskal-Wallis test as appropriate. ${ }^{*} \mathrm{p}<0.05$. ${ }^{\mathrm{a}} \mathrm{A}$ decrease of $\geq 25 \%$ in eGFR or starting dialysis. ${ }^{b}$ Hypoalbuminemia or hyperkalemia.

summarized. Statistical significance was defined as $\mathrm{p}<0.05$. These analyses were conducted using SAS, version 9.2 (SAS, Inc., Cary, N.C., USA).

\section{Results}

217 CKD patients were included in the analysis. Patient demographics including biochemical data are shown in table 1 . The causes of CKD were as follows: diabetic nephropathy, 68 patients, $31.3 \%$; chronic glomerulonephritis, 76 patients, $35.0 \%$; others, 73 patients, $33.7 \%$. Within 1 year, 49 patients $(22.6 \%)$ showed a decrease of $25 \%$ in their eGFR and 10 patients $(4.6 \%)$ started dialysis. 59 patients $(27.2 \%)$ reached the outcome. None of the patients died.

Diet Acid Load and CKD Progression
The baseline characteristics of the patients are shown in table 1 . The four groups did not show significant differences in age; gender; prevalence of DM; BMI; serum albumin, sodium, and potassium levels; $24 \mathrm{~h}$ urinary protein excretion level; protein intake level and number of RAAS inhibitor users. Group 4 showed a lower eGFR, larger number of patients in stage 5, lower bicarbonate level, higher potassium excretion level, larger number of loop diuretics users, and larger number of sodium bicarbonate users than group 1. The dose of sodium bicarbonate in group 1 was from 0 to $3 \mathrm{~g} /$ day, and in group 4 from 0 to $4.5 \mathrm{~g} /$ day.

A larger number of patients reached the outcome in groups 3 and 4 than in group 1 . The rates of reaching the outcome were as follows: for all groups, 0.31 person/year; group 1, 0.18 person/year; group 2, 0.22 person/year; group 3, 0.44 person/year, and group 4, 0.42 person/year. 
Table 2. High NEAP was associated with CKD progression

$\begin{array}{lllll}\text { HR } & \text { 95\% CI } & \mathrm{p} & \text { Adjusted HR } & 95 \% \mathrm{CI}\end{array}$

A. Results of analysis using Cox proportional hazards models for baseline groups Group 1 ref ref

$\begin{array}{lllllll}\text { Group 2 } & 1.216 & 0.504,2.935 & 0.66 & 0.971 & 0.390,2.419 & 0.95 \\ \text { Group 3 } & 2.465 & 1.122,5.414 & 0.024^{*} & 2.046 & 0.914,4.579 & 0.082 \\ \text { Group 4 } & 2.358 & 1.066,5.213 & 0.034^{*} & 1.794 & 0.759,4.243\end{array}$

B. Results of analysis using extended Cox models for time-dependent NEAP groups ${ }^{\text {a }}$

Group 1 ref ref

$\begin{array}{llllll}\text { Group 2 } & 3.638 & 1.807,7.322 & 0.0003^{*} & 3.930 & 1.914,8.072 \\ \text { Group 3 } & 3.707 & 1.785,7.699 & 0.0004^{*} & 4.740 & 2.196,10.288 \\ \text { Group 4 } & 4.777 & 2.404,9.493 & 0.0001^{*} & 4.303 & 0.0002^{*} \\ & & & & \end{array}$

Values are given as HRs (95\% CI). The Cox proportional hazards models and the extended Cox models are adjusted for baseline eGFR, serum bicarbonate level, $24 \mathrm{~h}$ urinary protein excretion level, and furosemide use. Patients were categorized into four groups on the basis of quartiles of NEAP. In the analysis using extended Cox models, groups were treated as time-dependent variables. ${ }^{*} \mathrm{p}<0.05$. a NEAP groups categorized on quartiles of NEAP at baseline.

Fig. 1. Kaplan-Meier analysis of CKD progression-free survival in groups categorized on the basis of quartiles of NEAP at baseline. CKD progression $=$ reaching the outcome; survival probability = probability of being CKD progression-free; groups $1-4$ = groups categorized on quartiles of NEAP at baseline.

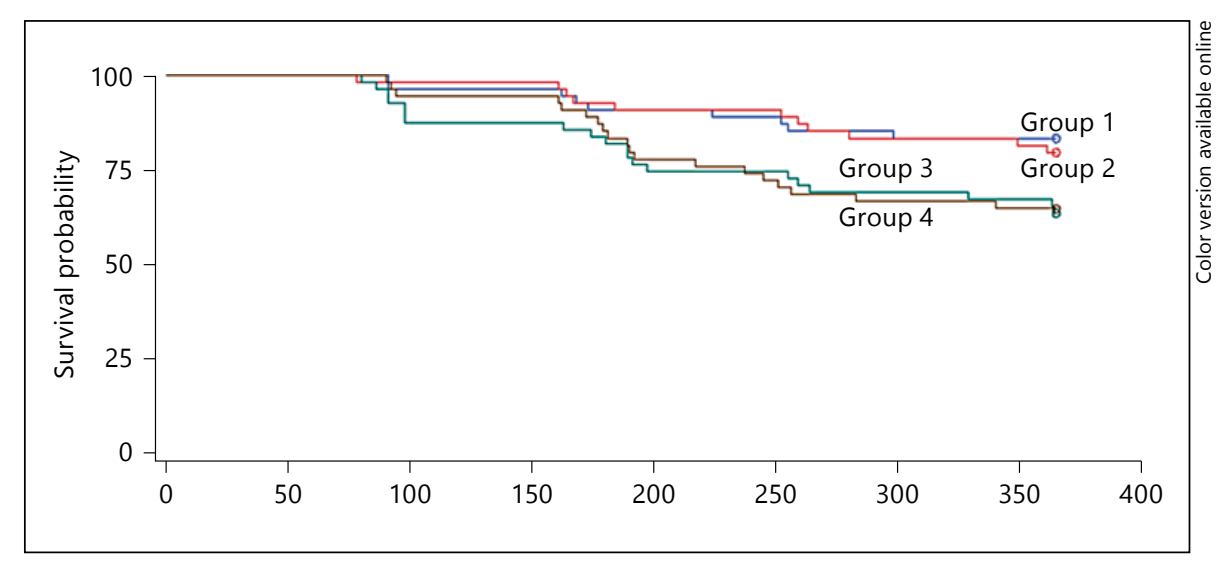

\section{NEAP and CKD Progression}

Kaplan-Meier analysis showed a significant difference in the outcome among the groups (log-rank test $p=0.036$; fig. 1). Univariate Cox proportional hazards models showed that eGFR $(\mathrm{p}=0.047)$, serum bicarbonate level $(\mathrm{p}=0.027), 24 \mathrm{~h}$ urinary protein excretion level $(\mathrm{p}=$ $0.022)$, and furosemide use $(\mathrm{p}=0.049)$ were significant variables. A Cox proportional hazards model adjusted for baseline variables suggests that, on the basis of eGFR, serum bicarbonate level, $24 \mathrm{~h}$ urinary protein excretion lev$\mathrm{el}$, and furosemide use, group 3 was at a high risk of the outcome (table 2A). An extended Cox model for timedependent NEAP groups showed that groups 2-4 were associated with a high risk of the outcome after adjustment for baseline variables, namely eGFR, serum bicar- bonate level, $24 \mathrm{~h}$ urinary protein excretion level, and furosemide use (table $2 \mathrm{~B}$ ).

We conducted a similar survival analysis with stratification by serum bicarbonate level (table 3). Extended Cox models for time-dependent NEAP groups showed that groups 2-4 were associated with a high risk of the outcome in patients regardless of serum bicarbonate level after adjustment for baseline eGFR, $24 \mathrm{~h}$ urinary protein excretion level, and furosemide use (table $3 \mathrm{~B}$ ). We then evaluated the effect of sodium bicarbonate use on CKD progression. In the eight stratums based on NEAP and serum bicarbonate level, Kaplan-Meier analysis showed no statistically significant difference in the outcome between sodium bicarbonate use and non-sodium bicarbonate use. 
Table 3. High NEAP was associated with CKD progression in patients regardless of serum bicarbonate levels

\begin{tabular}{|c|c|c|c|c|c|c|}
\hline & HR & $95 \% \mathrm{CI}$ & $\mathrm{p}$ & Adjusted HR & $95 \% \mathrm{CI}$ & $\mathrm{p}$ \\
\hline \multicolumn{7}{|c|}{ A. Results of analysis using Cox proportional hazards models for baseline groups categorized by serum bicarbonate level } \\
\hline \multicolumn{7}{|c|}{ Low serum bicarbonate levels } \\
\hline Group 2 & 3.892 & $0.405,37.420$ & 0.24 & 0.532 & $0.176,1.613$ & 0.27 \\
\hline Group 3 & 8.107 & $0.946,69.450$ & 0.056 & 0.721 & $0.263,1.979$ & 0.53 \\
\hline Group 4 & 24.367 & $2.692,220.519$ & $0.0045^{*}$ & 0.999 & $0.367,2.722$ & 0.99 \\
\hline Group 1 & ref & & & ref & & \\
\hline Group 2 & 1.930 & $0.432,8.622$ & 0.39 & 1.870 & $0.418,8.362$ & 0.41 \\
\hline Group 3 & 6.418 & $1.736,23.731$ & $0.0053^{*}$ & 6.169 & $1.666,22.851$ & $0.0065^{*}$ \\
\hline Group 4 & 4.265 & $1.018,17.858$ & $0.047^{*}$ & 3.376 & $0.764,14.908$ & 0.11 \\
\hline \multicolumn{7}{|c|}{$\begin{array}{l}\text { B. Results of analysis using Cox proportional hazards models for time-dependent NEAP groups categorized by serum bicarbonate level } \\
\text { Low serum bicarbonate levels }\end{array}$} \\
\hline \multicolumn{7}{|c|}{ High serum bicarbonate levels } \\
\hline Group 1 & ref & & & ref & & \\
\hline Group 2 & 9.120 & $2.742,30.339$ & $0.0003^{*}$ & 9.445 & $2.738,32.588$ & $0.0004^{*}$ \\
\hline Group 3 & 8.205 & $2.312,29.115$ & $0.0011^{*}$ & 7.970 & $2.229,28.501$ & $0.0014^{*}$ \\
\hline Group 4 & 14.077 & $3.139,63.121$ & $0.0006^{*}$ & 11.459 & $2.494,52.656$ & $0.0017^{*}$ \\
\hline
\end{tabular}

Patients were stratified into two groups on the basis of the serum bicarbonate level: low serum bicarbonate levels, 22-26.15 mEq/l; high serum bicarbonate levels, $>26.15 \mathrm{mEq} / \mathrm{l}$. Values are given as HRs $(95 \% \mathrm{CI})$. The Cox proportional hazards models and the extended Cox models are adjusted for baseline eGFR, $24 \mathrm{~h}$ urinary protein excretion level, and furosemide use. ${ }^{*} \mathrm{p}<0.05$. Groups were categorized on quartiles of NEAP at baseline.

\section{Complications}

The NEAP-related complications mainly observed were hypoalbuminemia and hyperkalemia. These complications were more frequently observed in groups 3 and 4 than in group 1 (table 1). The proportions of patients whose complications persisted from the baseline to 3 months later were high in groups 3 and 4 (fig. 2). New complications were more frequently observed in the group 4 than in other groups (fig. 2). Univariate logistic regression analysis showed that complications in the third month were associated with the group, gender, eGFR, serum bicarbonate level, $24 \mathrm{~h}$ urinary protein excretion level, sodium bicarbonate use, and the presence of complications at baseline (table 4). Analysis using multivariate logistic regression model including gender, eGFR, serum bicarbonate level, $24 \mathrm{~h}$ urinary protein excretion level, sodium bicarbonate use, and the presence of complications at baseline showed that serum bicarbonate level and the presence of complications at baseline were independently associated with complications (table 4).

Diet Acid Load and CKD Progression

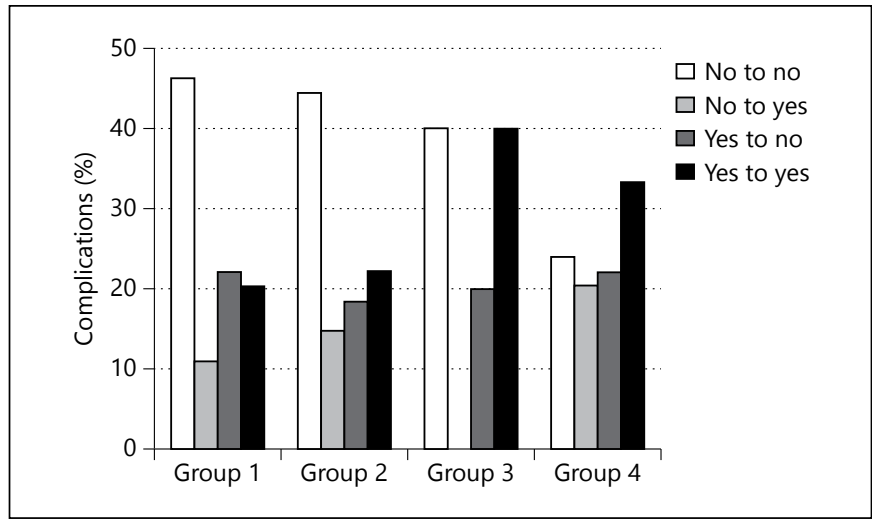

Fig. 2. Changes in prevalence of complications (hypoalbuminemia or hyperkalemia) from baseline to the third month in groups categorized on the basis of quartiles of NEAP at baseline. No to no = patients who have no complications from baseline to the third month; No to yes = patients who had no complications at baseline, but had complications at the third month; Yes to no = patients who had complications at baseline, but had no complications at the third month; Yes to yes = patients who have complications from baseline to the third month; groups 1-4 = groups categorized on quartiles of NEAP at baseline. 
Table 4. Complications in the third month correlated with serum bicarbonate level and the presence of complications at baseline

\begin{tabular}{|c|c|c|c|c|c|c|}
\hline & OR & $95 \% \mathrm{CI}$ & $\mathrm{p}$ & Adjusted OR & $95 \% \mathrm{CI}$ & $\mathrm{p}$ \\
\hline Group 1 & ref & & & ref & & \\
\hline Group 2 & 1.280 & $0.577,2.840$ & 0.57 & 1.119 & $0.430,2.911$ & 0.93 \\
\hline Group 3 & 1.451 & $0.660,3.190$ & 0.95 & 0.972 & $0.383,2.471$ & 0.56 \\
\hline Group 4 & 2.525 & $1.152,5.534$ & $0.024^{*}$ & 1.593 & $0.615,4.128$ & 0.25 \\
\hline Male $($ ref $=$ female $)$ & 2.126 & $1.070,4.225$ & $0.031^{*}$ & 1.388 & $0.624,3.085$ & 0.42 \\
\hline eGFR (per increase in $1 \mathrm{ml} / \mathrm{min} / 1.73 \mathrm{~m}^{2}$ increase) & 0.959 & $0.939,0.980$ & $0.0002 *$ & 0.987 & $0.957,1.018$ & 0.40 \\
\hline Bicarbonate level (per increase in $\mathrm{mEq} / \mathrm{l}$ ) & 0.744 & $0.659,0.841$ & $0.0001^{*}$ & 0.780 & $0.674,0.903$ & $0.0009^{*}$ \\
\hline \multicolumn{7}{|l|}{$24 \mathrm{~h}$ urinary protein excretion level } \\
\hline (per increase in $1 \mathrm{~g} /$ day) & 1.349 & $1.129,1.611$ & $0.001^{*}$ & 1.142 & $0.935,1.395$ & 0.19 \\
\hline Sodium bicarbonate use, yes $(\mathrm{ref}=\mathrm{no})$ & 1.728 & $0.902,3.313$ & 0.099 & 0.547 & $0.236,1.268$ & 0.16 \\
\hline Complications at baseline, yes $(\mathrm{ref}=\mathrm{no})$ & 4.704 & $2.613,8.469$ & $0.0001^{*}$ & 3.454 & $1.690,7.061$ & $0.0007^{*}$ \\
\hline
\end{tabular}

Adjusted OR was determined using a logistic regression model that includes gender, eGFR, serum bicarbonate level, 24 h urinary protein excretion level, sodium bicarbonate use, and complications at baseline as variables. * $\mathrm{p}<0.05$. Groups were categorized on quartiles of NEAP at baseline.

\section{Discussion}

In this study, we demonstrated that a high NEAP was associated with a high risk of CKD progression in elderly CKD patients by time-to-event analysis. Our study is the first to clarify this relationship in CKD patients on a lowprotein diet with normal serum bicarbonate levels. This study also showed that the prevalence of hypoalbuminemia or hyperkalemia was higher in the high NEAP groups than in the low-NEAP groups. However, the independent risk factor for the complications was not high NEAP, but low serum bicarbonate level and preexisting complications. These findings suggest that a low NEAP may safely prevent CKD progression in elderly CKD patients.

In this study, NEAP was found to be associated with renal events in CKD patients with normal serum bicarbonate levels after the adjustment for serum bicarbonate level, as well as also after the stratification of patients by serum bicarbonate level. AASK reported that a high NEAP is independently associated with a low serum bicarbonate level and a rapid decrease in GFR [12]. These findings suggest that NEAP is associated with the decrease in GFR, which may be independent of the decrease in serum bicarbonate level. Here, we hypothesize that there are two pathways by which NEAP leads to the decrease in GFR: (1) NEAP decreases serum bicarbonate level, which leads to the decrease in GFR and (2) NEAP directly leads to the decrease in GFR, not through the decrease in serum bicarbonate level (fig. 3).

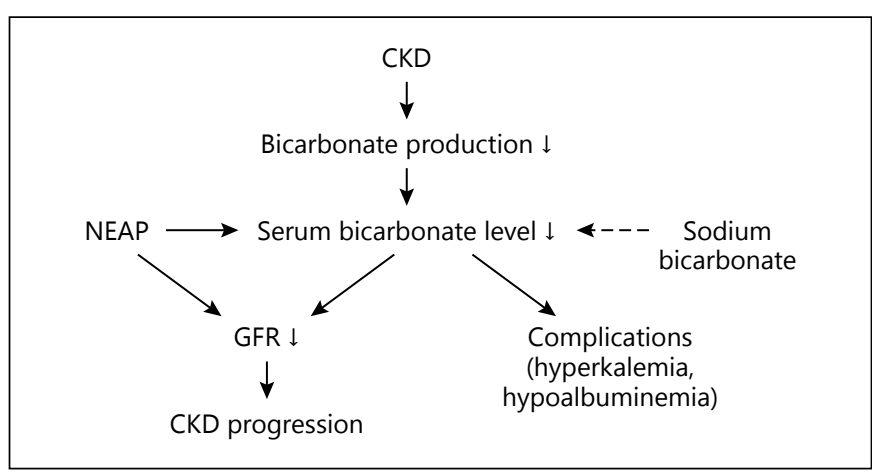

Fig. 3. Factors related to CKD progression and complications (hypoalbuminemia or hyperkalemia). There are two possible pathways from NEAP to the decrease in GFR and CKD progression: (1) serum bicarbonate level decreased by NEAP leads to the decrease in GFR or (2) NEAP directly leads to the decrease in GFR, not through the decrease in serum bicarbonate level. The dashed arrow shows that sodium bicarbonate prevents the decrease in serum bicarbonate level. NEAP is not directly associated with the complications.

Studies using animal models demonstrated some mechanisms underlying kidney injury by acidosis through a pathway without the decrease in serum bicarbonate level (fig. 3). The increase in renal medullary ammonia level resulting from the stimulation of ammonia production by dietary acid load activates an alternative complement pathway and causes progressive tubulointerstitial injury [16]. In addition, increased endothelin production in CKD mediates the tubulointerstitial injury and decreases GFR associ- 
ated with metabolic acidosis [17]. Dietary protein decreases in GFR as mediated by endothelin receptors $[18,19]$. An increased dietary protein level increases renal endothelin production, and distal nephron acidification is mediated by increased endothelin activity [19]. These findings suggest that NEAP affects CKD progression through distal nephron acidification and endothelin activation.

The mechanism underlying the renal protective effect of alkali therapy in humans has not been clarified yet. In this study, no statistically significant difference in CKD progression between patients using sodium bicarbonate and those not using it was observed. This finding suggests that sodium bicarbonate may prevent CKD progression by preventing the decrease in serum bicarbonate level (fig. 3). A prospective interventional study showed that sodium citrate decreases urine endothelin-1 excretion level and rate of GFR decrease [17]. It has been reported that the decrease in dietary acid level by the intake of fruit and vegetables decreases urinary endothelin- 1 and aldosterone levels in stage 2 CKD patients [20]. The decrease in acid level by alkali therapy may decrease kidney endothelin-1 and aldosterone levels in CKD patients by decreasing retained acid levels.

This study showed that the prevalence of complications, such as hypoalbuminemia or hyperkalemia, was not associated with NEAP but with serum bicarbonate level and preexisting complications. Acidosis enhances skeletal muscle protein catabolism and inhibits albumin synthesis [21]. A randomized clinical trial showed that bicarbonate supplementation improves dietary protein intake and inhibits protein catabolism with increased serum albumin level in CKD patients [22]. These results suggest that complications develop owing to insufficient neutralization by buffering systems in the whole body including bicarbonate buffering. However, even when serum bicarbonate level is kept within the normal range by the buffering systems in the body, it cannot be said that there is no acidosis in the body. Acid retention begins from an early CKD stage [23]. Local acidosis in the kidney causes kidney injury [24]. In our present study, no relationship between NEAP and the complications was observed. From previous studies, although the effect of NEAP may not be too strong to induce the development of complications owing to the buffering systems in the whole body, it may be strong enough to cause local acidosis in kidney and kidney injury (fig. 3). It would be valuable to determine whether treatment of acidosis by decreasing dietary acid level or medication with sodium bicarbonate before acidosis is observed in laboratory tests can prevent local kidney acidosis and kidney injury.

This study has several limitations. First, as with any observational study, we were unable to compare groups whose characteristics were controlled. Nonetheless, this study showed that NEAP was independently associated with CKD progression after the adjustment for patient characteristics. Second, we did not examine in detail the patients' food intake using diet records, and we were unable to evaluate the effect of different types of ingested protein on acid production. We did not restrict or recommend high-acid-containing proteins such as red meat. Because fish is common in traditional Japanese food, meat intake may be lower in the elderly in this study than in those in Western countries. Third, we were unable to compare NEAP between patients who were on a low-protein diet and those who were not, and unable to evaluate the effect of a low-protein diet on NEAP. Fourth, acidosis-related markers such as arterial blood gas and arterial $\mathrm{pH}$ were not measured.

In summary, our data showed that a high NEAP is a risk factor for CKD progression. The occurrence of hypoalbuminemia or hyperkalemia was not associated with NEAP. Decreasing NEAP may be an effective and safe kidney-protective therapy.

\section{Disclosure Statement}

The authors have no conflicts of interest to disclose.

\section{References}

1 Bailey JL: Metabolic acidosis: an unrecognized cause of morbidity in the patient with chronic kidney disease. Kidney Int 2005; 96(suppl):S15-S23.

$\checkmark 2$ Kraut JA, Kurtz I: Metabolic acidosis of CKD: diagnosis, clinical characteristics, and treatment. Am J Kidney Dis 2005;45:978993.
3 Kraut JA, Madias NE: Consequences and therapy of the metabolic acidosis of chronic kidney disease. Pediatr Nephrol 2011;26:1928.

$\checkmark 4$ Shah SN, Abramowitz M, Hostetter TH, Melamed ML: Serum bicarbonate levels and the progression of kidney disease: a cohort study. Am J Kidney Dis 2009;54: 270-277.
5 Kovesdy CP, Anderson JE, Kalantar-Zadeh K: Association of serum bicarbonate levels with mortality in patients with non-dialysis-dependent CKD. Nephrol Dial Transplant 2009; 24:1232-1237.

6 Menon V, Tighiouart H, Vaughn NS, Beck GJ, Kusek JW, Collins AJ, Greene T, Sarnak MJ: Serum bicarbonate and long-term outcomes in CKD. Am J Kidney Dis 2010;56:907-914. 
7 Raphael KL, Wei G, Baird BC, Greene T, Beddhu S: Higher serum bicarbonate levels within the normal range are associated with better survival and renal outcomes in AfricanAmericans. Kidney Int 2011;79:356-362.

8 Kanda E, Ai M, Yoshida M, Kuriyama R, Shiigai T: High serum bicarbonate level within the normal range prevents the progression of chronic kidney disease in elderly chronic kidney disease patients. BMC Nephrol 2013; 14:4.

9 Remer T: Influence of diet on acid-base balance. Semin Dial 2000;13:221-226.

10 Frassetto LA, Lanham-New SA, Macdonald HM, Remer T, Sebastian A, Tucker KL, Tylavsky FA: Standardizing terminology for estimating the diet-dependent net acid load to the metabolic system. J Nutr 2007;137:14911492.

11 Frassetto LA, Todd KM, Morris RC, Sebastian A: Estimation of net endogenous noncarbonic acid production in humans from diet potassium and protein contents. Am J Clin Nutr 1998;68:576-583.

12 Scialla JJ, Appel LJ, Astor BC, Miller ER, Beddhu S, Woodward M, Parekh RS, Anderson CA; Group AASoKDaHS: Net endogenous acid production is associated with a faster decline in GFR in African-Americans. Kidney Int 2012;82:106-112.
13 Scialla JJ, Appel LJ, Astor BC, Miller ER, Beddhu S, Woodward M, Parekh RS, Anderson CA: Estimated net endogenous acid production and serum bicarbonate in AfricanAmericans with chronic kidney disease. Clin J Am Soc Nephrol 2011;6:1526-1532.

14 Japanese Society of Nephrology: Evidencebased practice guideline for the treatment of CKD. Clin Exp Nephrol 2009;13:537-566.

15 K/DOQI National Kidney Foundation: Clinical practice guidelines for nutrition in chronic renal failure. Am J Kidney Dis 2000;35:S1S140.

16 Nath KA, Hostetter MK, Hostetter TH: Pathophysiology of chronic tubulointerstitial disease in rats. Interactions of dietary acid load, ammonia, and complement component C3. J Clin Invest 1985;76:667-675.

17 Phisitkul S, Khanna A, Simoni J, Broglio K, Sheather S, Rajab MH, Wesson DE: Amelioration of metabolic acidosis in patients with low GFR reduced kidney endothelin production and kidney injury, and better preserved GFR. Kidney Int 2010;77:617-623.

18 Phisitkul S, Hacker C, Simoni J, Tran RM, Wesson DE: Dietary protein causes a decline in the glomerular filtration rate of the remnant kidney mediated by metabolic acidosis and endothelin receptors. Kidney Int 2008;73: 192-199.
9 Khanna A, Simoni J, Hacker C, Duran MJ, Wesson DE: Increased endothelin activity mediates augmented distal nephron acidification induced by dietary protein. J Am Soc Nephrol 2004;15:2266-2275.

20 Goraya N, Simoni J, Jo C, Wesson DE: Dietary acid reduction with fruits and vegetables or bicarbonate attenuates kidney injury in patients with a moderately reduced glomerular filtration rate due to hypertensive nephropathy. Kidney Int 2012;81:86-93.

21 Williams B, Hattersley J, Layward E, Walls J: Metabolic acidosis and skeletal muscle adaptation to low protein diets in chronic uremia. Kidney Int 1991;40:779-786.

22 De Brito-Ashurst I, Varagunam M, Raftery MJ, Yaqoob MM: Bicarbonate supplementation slows progression of CKD and improves nutritional status. J Am Soc Nephrol 2009;20: 2075-2084.

23 Wesson DE, Simoni J, Broglio K, Sheather S: Acid retention accompanies reduced GFR in humans and increases plasma levels of endothelin and aldosterone. Am J Physiol Renal Physiol 2011;300:F830-F837.

24 Wesson DE, Simoni J: Acid retention during kidney failure induces endothelin and aldosterone production which lead to progressive GFR decline, a situation ameliorated by alkali diet. Kidney Int 2010;78:1128-1135. 